\title{
DILEMMA OF CHOICE BETWEEN BREASTFEEDING AND REPLACEMENT FEEDING AMONG HIV POSITIVE MOTHERS IN TANZANIA
}

\author{
DMSJ;19(2) 9-12 \\ http://dx.doi.org/10.4314/dmsj.v19i2.3 \\ Lazaro M. Mnongya $\{$ MD3 $\}$ \\ Institution: Muhimbili University of Health and Allied Sciences (MUHAS)
}

\section{ABSTRACT}

Breast milk provides all the nutrients needed during the first few months of life, and also contains agents that help protect against common childhood illnesses such as diarrhoea and respiratory infections.

The objective of the study is to express challenges facing HIV positive mothers in choosing between replacement feeding and breast-feeding in Tanzania from 1999-2011.

Breastfeeding is part of the fundamental human rights; the right to food and to health. In HIV+ mothers, if no antiretroviral drugs are being taken, breastfeeding for two or more years can double the risk of the baby becoming infected to around $40 \%$. But if the mother opts to breast-feed, she and her child must adhere $100 \%$ to ARV's throughout the breastfeeding time. But percentage of HIV+ breastfeeding mothers accessing ARV's in developing countries is only $59 \%$.

Replacement feeding is the only $100 \%$ effective way to prevent mother-to-child transmission of HIV after birth, but the risk of infant mortality from other illnesses such as diarrhoea must be taken into account. It was also advised that replacement feeding could take place where it was "acceptable, feasible, affordable, sustainable and safe."

Breastfeeding should be promoted as ideal for most babies in low and middle income countries. HIV positive mothers should be supported not only by their husbands and health personnel but also by the community in general to choose between breastfeeding and replacement feeding in order to ensure growth of the infant and to support the mother physically and mentally to attain that goal.

\section{INTRODUCTION}

Breast milk provides all nutrients needed during the first few months of life, and also contains agents that help protect against common childhood illnesses such as diarrhoea and respiratory infections. ${ }^{[1]}$ In 2000, the World Alliance for Breastfeeding Action (WABA) declared that breastfeeding is part of the fundamental human rights; the right to food and to health. So every infant is supposed to breastfeed exclusively for six (6) months followed by complementary feeding up to two (2) years or more ${ }^{[2]}$.

Emerging evidence suggests that breastfeeding can be made safer if either the mother or the infant takes antiretroviral medication during the period of breastfeeding. Such interventions, combined with the benefits of exclusive breastfeeding (EBF), offer an important opportunity to improve the HIV-free survival of future generations of HIV-exposed infants ${ }^{[1]}$.

Mother-to-child transmission (MTCT) of HIV, which can occur in utero, during delivery, or through breastfeeding, is responsible for most paediatric HIV infections. Each day, an estimated 2,200 children become infected with HIV worldwide, $90 \%$ of them in sub-Saharan Africa, where vertically acquired HIV remains a public health problem of large proportions. ${ }^{[3]}$ Short-course peripartum antiretroviral therapy reduces the risk for MTCT of HIV around delivery ${ }^{[4]}$. With an estimated rate of MTCT of $12 \%$ for antenatal women, it's estimated that 72,000 babies in Tanzania will acquire infection from their mothers per year, approximately 25,000 of them through breastfeeding ${ }^{[5]}$.

HIV positive women in low and middle-income countries are advised on infant feeding differently from those in high income countries due to the fact there are limited resources and infrastructure. It is known that there is little access to clean water, sanitation and health services in low and middle-income countries and that not breastfeeding greatly increases the risk of disease and death of the baby [6].

Correspondence to: lazaromnongya@yahoo.com

Key words: ARVs, HIV, Replacement feeding,

Breastfeeding.

\section{METHODOLOGY}

Literature review of articles published from various sources from 1999-2011, including relevant reports, bulletins and guidelines from the United Nations (UN), World Health Organization (WHO), Tanzania Demographic and Health Survey (TDHS 2004-2005, 2010); Mma Bana and Kesho Bora studies observing challenges facing HIV positive mothers in choosing between replacement feeding and breastfeeding.

Objective

The objective of the study is to express challenges facing HIV positive mothers in choosing between replacement feeding and breastfeeding in Tanzania from 1999-2011 and the way forward. 


\section{RESULTS}

\section{A.Replacement feeding}

Replacement feeding is the only $100 \%$ effective way to prevent mother-to-child transmission of HIV after birth, but the risk of infant mortality from other illnesses such as diarrhoea must be taken into account ${ }^{[5]}$.

WHO recommends that replacement feeding for women in low and middle-income countries should only be implemented if the following conditions which can be summarised as AFASS are fulfilled:

Acceptability: Breastfeeding is the norm in African cultures. A mother must be able to cope with stigma and discrimination and resist pressure from friends and relatives to breastfeed. Culturally, Africans believe in breastfeeding rather than replacement therapy, hence women who opt for replacement feeding face fierce reactions from the community ${ }^{[5]}$.

Feasibility: A mother who chooses replacement feeding must have adequate time, knowledge, skills and other resources to prepare the replacement food and feed her baby up to twelve (12) times in 24 hours. Unless refrigerated, prepared formula becomes unsafe after just two hours. It is better to feed with a cup than with a bottle because cups are easier to clean and promote greater interaction between the mother and her baby ${ }^{[6]}$.

Affordability: Someone has to pay for the ingredients, fuel, water and other equipment needed for replacement feeding. In Tanzania, the cost of infant formula alone is similar to the minimum urban wage (40-48 milk tins in 6 months@15,000-25,000Tsh) and is well beyond the reach of most families as only $20 \%$ of Tanzanians can afford it ${ }^{[6]}$.

Sustainability: Feeding an infant for the first six months of life requires around $20 \mathrm{~kg}$ of formula and regular access to water. Even a brief disruption in supplies may have serious health implications: the mother may decide to breastfeed exclusively, but may start giving her infant additional fluids because she does not believe she has enough breast milk. Only $35 \%$ of Tanzanians have access to piped water, $13 \%$ to protected wells and $6 \%$ to protected springs, leaving $46 \%$ accessing water whose safety is unknown ${ }^{[7]}$.

Safety: Replacement food should be nutritionally sound and free from germs. The water it is mixed with should be boiled, and utensils should be cleaned (preferably boiled) before each use. This means the mother must have access to a reliable supply of safe water and fuel.

\section{B.Breastfeeding}

Breast milk provides all of the nutrients needed during the first few months of life, and also contains agents that help protect against common childhood illnesses such as diarrhoea and respiratory infections.

Even with mothers' triple therapy and infants' monotherapy, the transmission rates during 6 months of exclusive breastfeeding are $0.3 \%, 1 \%$ and $3.92 \%$ in Botswana, Tanzania and Zambia respectively. If there are no ARV's, the transmission rate shoots up to $5.9 \%$ within 6 months of exclusive breastfeeding. ${ }^{[5]}$ If no antiretroviral drugs are being taken, breastfeeding for two or more years can double the risk of the baby becoming infected to around $40 \%{ }^{[6]}$.

With an estimated rate of MTCT of $12 \%$ for antenatal women, it's estimated that 72,000 babies in Tanzania will acquire infection from their mothers per year, and approximately 25,000 through breastfeeding ${ }^{[5]}$. The main challenge lies in increasing the availability of treatment in resource-limited countries. The expansion of ART and PMTCT services is currently hindered by poor infrastructure, limited human and financial resources, and poor integration of HIV-specific interventions within broader maternal and child health services ${ }^{[9]}$. For example Kilimanjaro with 546,767 people has only four PMTCT centers ${ }^{[5]}$.

Lack of support at community level: There is insignificant support for exclusive breastfeeding for the intended six months. Instead there is influence and pressure from family members (mother-in-law and mothers of the breastfeeding mothers) to introduce other liquid or solid food in conjunction with breastfeeding. ${ }^{[5]}$ The median duration of exclusive breastfeeding at national level is 2.4 months. ${ }^{[11]}$ This value is higher than the 1.8 months reported in the TDHS 2004-05; In Tanzania, 38\% of women exclusively breastfeed for six months ${ }^{[7]}$.

Stigmatization: Having $73 \%$ of mothers practicing mixed feeding poses a challenge to the mothers opting for exclusive breastfeeding whether HIV positive or HIV negative. For example, in the Breast Milk Study in Kampala, Uganda, some women experience domestic violence ranging from desertion, financial support withdrawal and battering following HIV status disclosure to their spouses ${ }^{[13]}$

.Counselor and supporter frustration: The counselors have the same stressful experiences as the mothers. A presentation on infant feeding counseling in Tanzania made similar observations, noting that counselors lacked confidence and had high levels of stress and frustration. A grave finding was that the counselors did not agree with exclusive breastfeeding or exclusive formula feeding ${ }^{[13]}$.

Malnutrition: Many women are concerned that their breast milk is not sufficient for their infant because they are malnourished. 16.1million (over 50\%) Tanzanians were undernourished during 2001-03, and the trend is growing [8].

Shortage of the human resource needed to counsel mothers on which method they should choose according to their economic status, social status and cultural background. Most counsellors are nurses who have a huge workload, are trained to cure patients not to counsel and few have adequate counselling knowledge. In a study done in Kilimanjaro (northern Tanzania), there were only four PMTCT sites, surrounded by 546,767 people and almost each PMTCT site usually counsels a maximum 12 women a day ${ }^{[5]}$.

Poverty: While traditionally the confinement period was six months, very few families can afford to have such a long 
period of rest after delivery these days. As one quoted ' Nowadays most mothers don't stay indoors for more than two months after delivery, they're expected to go out to work so that they can supplement the family income as life is becoming more and more expensive $\mathrm{e}^{[5]}$.

Expression of breast milk: If the mother is working most of the time, it's better to express milk from the breasts and store it in refrigerators to be given to the infant later than not breastfeeding at all. That's culturally unaccepted in most regions of Tanzania as expression of breast milk is considered abnormal and is highly associated with death of the infant as one quoted in Kilimanjaro 'She becomes a witch-she doesn't crave for the survival of the child ${ }^{[5]}$.

\section{DISCUSSION AND RECOMMENDATIONS}

This review examines challenges facing HIV positive mothers in choosing between Breastfeeding and Replacement feeding in Tanzania and the way forward.

National health authorities are encouraged by WHO to identify the most appropriate infant feeding practices (either breastfeeding with ARV's or the use of infant formula) for their communities ${ }^{[9]}$. The selected practice should then be promoted as the single standard of care. Tanzania has not yet come out with the correct answer to that dilemma; instead we have left counselors and mothers to choose by themselves. The government should come out with the final decision.

Mothers should ensure good attendance at the Antenatal Clinic (ANC) for healthy delivery, counseling, monitoring of progress as well as sustainable access to ARV's. It was observed in Kigoma that $96 \%$ of pregnant women attended ANC and $94 \%$ of them were attended to by trained health personnel who have a great opportunity to educate the community on EBF. $\left[{ }^{10,15]}\right.$ Also they should make sure that they adhere to a balanced diet which is accessible in their surroundings to avoid malnutrition.

It is important to increase health personnel in PMTCT. HIV counselling should be included in the teaching curriculum of medical personnel so as to equip them with adequate knowledge to serve and save the society. Education is also important in the general community as depicted in the study done in Kigoma region where moderate knowledge was $78 \%$ and exclusive breastfeeding was $58 \%$, higher than the national level which is $41 \%{ }^{[15]}$.

The government should provide free replacement feeds both in rural and urban areas so that it is easy for mothers who opt for replacement therapy to have access to feeds. The community should avoid stigmatizing HIV positive mothers so that they can freely practice their chosen method of infant feeding. As quoted in the study done in South Africa "when they see me coming with the tins they laugh at me" ${ }^{[17]}$.

The community should be well educated about the importance of both breastfeeding and replacement feeding for HIV positive mothers, and not just campaigning for exclusive breastfeeding for 6 months.
HIV-infected pregnant women in need of ART for their own health should start ART as soon as feasible regardless of gestational age and continue throughout pregnancy, childbirth, breastfeeding (if breastfeeding), and thereafter. ${ }^{[12]}$. All infants (regardless of whether breastfeeding or receiving only replacement feeding) born to HIV-infected women receiving ART for their own health should be given daily NVP or twice-daily AZT from birth or as soon as feasible thereafter until 4 to 6 weeks of age ${ }^{[14]}$.

\section{CONCLUSION}

The option to breastfeed or not depends on the economic and health status of the mother, community support, health service availability, good hygiene and good sanitation.

Breastfeeding should be promoted as ideal for most babies in low and middle income countries, and adherence to ARV.HIV positive mothers should be supported not only by their husbands and health personnel but also by the community in general to choose between breastfeeding and replacement feeding in order to promote growth of the infant and to support the mother physically and mentally to attain her goal.

\section{REFFERENCE}

1.Shapiro RL, Hughes MD, Ogwu A, et al Antiretroviral Regimens in Pregnancy and Breast-Feeding in Botswana. 2010 New England Journal of Medicine 362:2282-94.

2.Holla-Bhar R: Against all odds: Gendered challenges to breastfeeding. World Alliance for Breastfeeding Action (WABA) and Centro Feminista de Information y Accion (CEFEMINA) Costa Rica. 2nd ed. June 2006.

3.United Nations Program on HIV/AIDS: AIDS epidemic update. Geneva,Switzerland: United Nations Program on HIV/AIDS; 2006.

4.Leroy V, Sakarovitch C, Cortina-Borja M, et al. Is there a difference in the efficacy of peripartum antiretroviral regimens in reducing mother-to-child transmission of HIV in Africa? AIDS 2005; 19:1865-1875.

5. Sebalda C. Leshabari, Astrid Blystad, Marina de Paoli, Karen M Moland: HIV and infant feeding counseling: challenges faced by nurse counselors in northern Tanzania. Human Resource for Health 2007, 5:18.

6.UNICEF / UNFPA / WHO: HIV transmission through breastfeeding. 2007

7.Tanzania Demographic Health survey 2004-2005. National Bureau of statistics. Dar es salaam, Tanzania, Calverton, Maryland, Bureau of statistics and Macro International: TDHS-2005.

8.Sullivan Arthur, Steven M. Sheffrin: Economic principles in action, upper saddle river, New Jersey 07458: Pearson Prentice Hall. 2003, pp 481. 
9.WHO/UNAIDS/UNICEF: Global HIV/AIDS Response: Epidemic update and health sector progress towards Universal Access 2011. 2011

10. Ruth M. Bland, Kirsty E. Little, Hoosen M. Coodia, Anna Coutsoudis, Nigel C. Rollis, Marie-Louse Newell "Intervention to promote exclusive breast-feeding for the first 6 months of life in a high HIV prevalence area". 2008, AIDS 22(7) 883-891.

11. Tanzania Demographic Health Survey: complementary and breast feeding. TDHS-2010,

12. Coutsoudis A, Pillary K, Spooner E, Kuhn L, Coovadia HM: Influence of infant-feeding patterns on early motherto-child transmission of HIV-1 in Durban, South Africa, in a prospective cohort study. South African Vitamin A study group. Lancet 1999,354(9177):471-476.
13. Greiner T: HIV-infant feeding: More on problems with replacement feeding in Botswana. 2006, HATIP \#76

14.WHO: New HIV recommendations to improve health, reduce infections and save lives; World AIDS Day, 2009.

15. Tiras E. Enkala, Sia E. Msuya: Prevalence and predictors of exclusive breastfeeding among women in Kigoma region, western Tanzania: a community based crossectional study. International Breastfeeding Journal, 2011, 6:7.

16. Aidam BA, Pe'rez-Escamilla R, Lartey A: Lactation counseling increases exclusive breastfeeding rates in Ghana. Journal of Nutrition, 2005, 135(7):1691-1695.

17. Doherty T, Chopra M, Nkoli L, Jackson D, Greiner T: Effect of HIV epidemic on infant feeding in south Africa: "When they see me coming with the tins, they laugh at me”,Bull Worls Health Organ 2006, 84(2):90-96. 